\title{
Relationship between gestational diabetes and pregnancy induced hypertension (PIH)
}

\author{
*Sajida Perveen ${ }^{1}$, Qaiser jabeen ${ }^{1}$ and Muhammad Zahid Iqbal ${ }^{2}$ \\ ${ }^{1}$ Department of Pharmacy, Faculty of Pharmacy and Alternative Medicine, The Islamia University of Bahawalpur, Pakistan \\ ${ }^{2}$ Department of Clinical Pharmacy and Pharmacy Practice, Faculty of Pharmacy, AIMST University, Kedah Darul Aman, Malaysia
}

\begin{abstract}
Pregnancy-induced hypertension (PIH) and gestational diabetes mellitus (GDM) both have no adequate classification in addition to nomenclature that creates difficulties for researchers to find link between them. Aim of this work was to review the most recent data available on PIH and GDM and find the association between both conditions during gestation. Epidemeologies and whole studies which have done till now days, could not satisfy that what is association between PIH and GDM. The main issue to solve is how to find the association between GDM and PIH. Very limited data and research studies are available, creating hindrance to find any association. The one way to find the association now, can be that it should be checked the level of hypertension before, during and after gestation. According to the available data and research, it could be deduced that insulin resistance, present in non-insulin dependent diabetes mellitus (NIDDM), may provide association more frequently. However, no direct evidential data is available for this link.
\end{abstract}

Key Words: Gestational diabetes, hypertension, pregnancy

\section{INTRODUCTION}

\section{Gestational diabetes}

Any degree of glucose intolerance that has its onset or is first detected during pregnancy indicates gestational diabetes. It occurs in approximately $2-7 \%$ of pregnant women, generally during the second or third trimester. Occurrence of gestational diabetes mellitus (GDM) increases future risk for developing type 2 diabetes mellitus (Bellamy et al., 2009). GDM can be managed by meal planning, physical activity and insulin as well, to decrease the complications in maternal and fetus. Over weighed diabetes in family history, race/ethnicity, 25 years or more age, previous delivered baby with weight 9 pounds or pre-diabetic gestational patients are risk factors and may increase the complications of GDM in any pregnant woman. Tight glycemic control with normal HBA1c levels is very important during pregnancy.

\section{Diagnostic criteria}

The most commonly used standard oral glucose tolerance test (OGTT), should be performed after overnight fasting (8-14h) by using $75 \mathrm{~g}$ anhydrous glucose in $300 \mathrm{ml}$ water and after $2 \mathrm{~h}$ plasma glucose level is measured (Alberti et al., 1998; Metzger et al., 1998). The most commonly used OGTT to diagnose GDM is the 3-hour, 100-g OGTT. According to the recommendations for diagnostic criteria by American Diabetes Association (ADA), GDM is diagnosed if, two or more plasma glucose levels, equal to or greater than the brink (table 1): at fasting $95 \mathrm{mg} / \mathrm{dl}$ of glucose concentration, at $1 \mathrm{hr} 180 \mathrm{mg} / \mathrm{dl}$ of glucose concentration, at $2 \mathrm{hr} 155 \mathrm{mg} / \mathrm{dl}$ of glucose concentration or at $3 \mathrm{hr} 140 \mathrm{mg} / \mathrm{dl}$ of glucose concentration (Tracyl. Setji et al., 2005; American et al., 2000; Metzger et al., 1998). Most recently, panel of WHO, characterizes GDM as

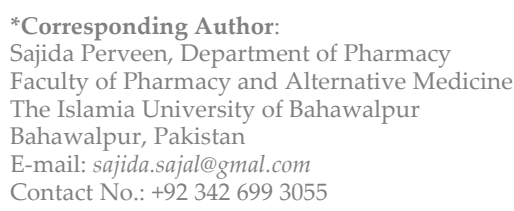

Impaired Glucose Tolerance (IGT) or Fasting Glucose level $\geq 7.0 \mathrm{mmol} / \mathrm{L}$ or $2 \mathrm{hr}$ glucose $\leq 7.8 \mathrm{mmol} / \mathrm{L}$ (WHO, 1999). OGTT is more sensitive as compared to fasting plasma glucose (FGP). FGP is more accepted in women due to less time period and easiness of tolerance. Both the ADA and WHO criteria are valid options for the diagnosis of GDM and the prediction of unfavorable pregnancy outcomes. Throughout pregnancy, hyperglycemia may lead to congenital abnormalities in the fetus, so a tight glycemics control should be there in gestational patient.

Complications \& risks of gestational diabetes mellitus Poor glycemic control in early on pregnancy increases the unplanned abortion as well as innate malformations. While, late in pregnancy, poor management of glycaemia may possibly lead towards polyhydranomias, preterm labor, still birth along with fetal macros Omnia with its associated problems. Diabetic retinopathy can first develop for the duration of pregnancy or retinopathy that is already present can be proved as worsen. Diabetic women with microalbumin urea can have worsening albumin urea during pregnancy and are at higher risk for pre-eclampsia. Patients who have pre-existing renal failure are at increased risk of kidney function turn down during pregnancy and this may not reverse after delivery. Diabetic gastroparesis can severely exacerbate nausea and vomiting of pregnancy. Some patients may need nutritional support.

Unless, there are fetal and maternal complications, diabetic women should be capable of carrying the pregnancy up to full term, delivering at 38-41 weeks. Induction of labor before 39 weeks may be cautious if there is concern about increase fetal heaviness.

Major and most common complications are intrauterine growth retardation, fetal depression, abnormal birth weight, premature birth and the very critical is intrauterine death. These complications may be greater hazards in an augmentation of morbidity as well as mortality due to exacerbation in coronary heart diseases (Naveed, 2002). Recently available epidemiological 
evidences shows that intrauterine growth retardation (IUGR), having a greater risk in pre-eclampsia caused by expansion of cardiovascular diseases in the life of adults (Fiona et al., 1996).

Several studies are present which represent that gestational diabetes mellitus GDM is 3-6\% risky to develop complications in infants of that mother (Moshehod et al., 1991). During a study, comparison of gestational diabetes mellitus $(\mathrm{n}=878)$ in which 132 mothers with pre-GDM and 380 as control, determined that more incidence of complications, such as: hypocalcaemia, hypoglycemia (neurological damage), macrosomia, birth trauma to mother and neonate (Moshehod et al.,1991; Spellacy et al.,1985), hyperbilirubinemia, polycythemia (neurological damage and renal vein thrombosis), Thrombocytopenia, and other congenital anomalies (Moshehod et al., 1991 ).Complications with the rates: preeclampsia or pregnancy induced hypertension (PIH) $24.6 \%$, cesareans $45.2 \%$ have been recorded. PIH occurs most frequently with significance of $(p<0.01)$ in patients with diabetic microangiopathy (Ulfhanson et al., 1993).

\section{Congenital anomalies}

Congenital anomalies includes CNS abnormalities (neural tube defects, 4.2 fold greater as compared to other anomalies (atlas et al., 2006; Christofer et al., 2000; Leanny et al., 2007), facial defects $85 \%$, eye anomalies $48 \%$, ear anomalies 95\%, gastrourinary anomalies 19\%, skeletal anomalies 52\%, cardiovascular malformations(CVM) including mitral valve, aortic valve and vascular disruption) (atlas et al., 2006; Christofer et al., 2000 ), diabetes associated heart malformations, 3.4 fold than other anomalies (Christofer et al., 2000; Leanny et al., 2007); left sided obstructive heart defects (Christofer et al., 2000), gastrointestinal anomalies (pyloric stenosis, small bowel atresia, mekel diverticulum, small colon syndrome), and skin anomalies (Atlas et al., 2006), reno-genital and aneuploidy (Ferral et al., 2002).

\section{Pregnancy induced hypertension (PIH)}

A syndrome of hypertension with or without proteinuria and edema during gestation is known as pregnancy induced hypertension (PIH). It usually occurs with some clinical menifestations (Jun Zhang et al., 1997). Hypertension develops after 20 weeks of gestation categorized as $\mathrm{PIH}$. Approximately, all forms of PIH are present combine in $8 \%$ of pregnancies by epidemiological point of view (Girouard et al., 2007).

\section{Classification of PIH}

Four forms of PIH are present, preeclampsia, eclampsia, chronic hypertension and gestational hypertension. In underdeveloped countries, preeclampsia is a major cause of fetal and maternal morbidity and mortality (Baha et al., 1995; Fiona et al., 1996). In pre-eclampsia, characteristics are high blood pressure in last trimester of gestation $(90$ $\mathrm{mmHg}$ or an increase of $25 \mathrm{mmHg}$ with the presence of protein uric level $(0.3 \mathrm{~g}$ per $24 \mathrm{hr})$ with instabilities of body systems. It can lead to eclampsia, i.e., grand mal convulsions (Fiona et al., 1996). These all classes of PIH can be defined as in table 2 .

\section{Incidence}

Multiple pregnancies have more risk of PIH as compared to the single gestational women. The risk in smokers to have PIH has been observed consistently lower than the non-smokers (Jun Zhang et al., 1997).
Table 1: Diagnosis of GDM by OGTT.

\begin{tabular}{|c|c|c|c|}
\hline & $\begin{array}{c}\text { ADA } \\
\text { 100-g OGTT }\end{array}$ & $\begin{array}{c}\text { ADA } \\
\text { 75-g OGTT }\end{array}$ & $\begin{array}{c}\text { WHO } \\
\text { 75-g OGTT }\end{array}$ \\
\hline Fasting (mg/dl) & 95 & 95 & 126 \\
\hline 1-hour (mg/dl) & 180 & 180 & - \\
\hline 2-hour (mg/dl) & 155 & 155 & 140 \\
\hline 3-hour (mg/dl) & 140 & - & - \\
\hline \multicolumn{4}{|c|}{$\begin{array}{l}\text { For the ADA criteria, two or more of the values from either the } 100-\text { or } 75 \text {-g OGTT must } \\
\text { be met or exceeded to make the diagnosis of GDM. For the WHO criteria, one of the two } \\
\text { values from the } 75 \text {-g OGTT must be met or exceeded to make the diagnosis of GDM. }\end{array}$} \\
\hline
\end{tabular}

Table 2: Widely used definitions of PIH forms.

\begin{tabular}{|c|c|c|}
\hline & $\begin{array}{c}\text { American college of } \\
\text { Obstetrics and gynaecologist }\end{array}$ & Oxford \\
\hline Hypertention & $\begin{array}{l}\mathrm{SBP}^{*} \geq 30 \mathrm{mmHg} \text { or } \\
\mathrm{DBP}^{* *} \geq 15 \mathrm{mmHg} \text { or } \\
\text { B.P } \geq 140 / 90 \mathrm{mmHg}\end{array}$ & $\begin{array}{l}\text { Initial } \mathrm{B} . \mathrm{P}<90 \mathrm{~mm} \\
\mathrm{Hg} \text { giving rise to } \\
\text { maximum of } \\
\geq 90 \mathrm{~mm} \mathrm{Hg}\end{array}$ \\
\hline Gestational & Hypertension without & Hypertension only \\
\hline Hypertension & Proteinuria & \\
\hline preeclampsia & $\begin{array}{l}\text { Hypertension with pro- } \\
\text { teinuria \&/or edema }\end{array}$ & $\begin{array}{l}\text { Hypertension with } \\
\text { proteinuria }\end{array}$ \\
\hline eclampsia & Preeclampsia with seizures & - \\
\hline
\end{tabular}

Table 3: characteristic features of insulin resistance syndrome in association with a class of PIH (preeclampsia).

\begin{tabular}{ll|}
\hline - & Hypertension \\
- & Hyperinsulinemia \\
- & Glucose intolerance \\
- & Lipid abnormalities \\
- & Increase leptin \\
- & Increase TNF- $\alpha$ \\
- & Increase PAI-1 \\
- & Increase testosterone \\
Source: Seely et al., 2001.
\end{tabular}

\section{Epidemeology}

Epidemiologies of PIH have a number of factors which are recognized during a number of researches by different researchers at different time and areas of the world. We cannot say that a single or a specific kind of factor will be present in this condition.

\section{Factors for epidemeology}

Unlimited and uncountable factors are present to describe the epidemiology of pregnancy induced hypertension. Some of them are genetic factors e.g., family history, immune response, genetic variation, antioxidant enzymes, unprotected sexual intercourse, abortion in past, assisted reproductive technology, anti-phospholipid antibodies, age of maternity, obesity (risky for maternal body mass index) (Jun Zhang et al., 1997), polyhydramnios and hydrops fetalis, multiple pregnancies, race/ethnicity, smoking, low dose aspirin and supplementation, high altitude, stressful environment (Roberts, 2003).

\section{PIH and insulin resistance}

A greater degree of insulin resistance is present in $\mathrm{PIH}$, by different mechanisms of insulin such as associated endothelial dysfunction, sodium retention in kidneys, activation of sympathetic nervous system, and increased level of transportation of cations. 
GDM provide an increased risk of $\mathrm{PIH}$, due to increase in insulin resistance due to $\beta$-cell defects (Thomas et al., 2007) leading to hyperglycemia (non-insulin dependent diabetes mellitus). The results of an approach in China indicated that insulin resistance and hyperinsulinemia are present in severe PIH patients, after an oral glucose load (Gu H et al., 1994; Kim et al., 1999). It is also evident that hyperinsulinemia and insulin resistance play a role in hypertension development (James et al., 2003). Insulin resistance have been associated with some markers in body such as, leptin, adiponeptin, tumor necrotic factor (TNF- $\alpha$ ), platelet activating inhibitor (PAI1), homocysteine (Palomo et al., 2006; Joe et al., 2003), which have been studied during or after pregnancy/in postpartum period (Girourd et al., 2007).

\section{RESEARCH (STUDY DESIGNS) ON PIH}

Very limited research and evidential data is available. One of these is given: a retrospective cohort study was conducted by Xu Xiong et al., in 1989-1990 on the basis of births from population based perinatal database in china, which resulted that 0.6 week shorter gestation in state of preeclampsia as compared to normotensive women $(p<0.1)$. So, it concludes that pre-eclampsia increases the risk of intrauterine growth restriction as well as low birth weight.

\section{Association between gestational diabetes and pregnancy induced hypertension}

Some researchers have been trying to find the clear relation between PIH and GDM through their researches, but still the results are unclear due to lack of a number and frequency of studies on these two fetal conditions, in maternal as well as fetuses.

\section{Study designs for relation between PIH and GDM}

A study conducted by Chris L. Bryson et al., in 1992-1998 in Washington state to assess the relation between gestational diabetes and pregnancy induced hypertension $(n=62,982)$ by using a birth events records database (BERD). It shows after adjustment for confounders, 1.5 times greater risk for developing serious disorders among gestational diabetics and both ethnicity and prenatal care modify the association between GDM and PIH.

Another study was performed in association between PIH and GDM Mocarski and Savitz DA. in Columbia University, New York (NY), USA on basis of birth certificate data during 2001-2006.To evaluate crude and adjusted OR of GDM, logistic regression was used among all ethnic groups. The adjusted OR ranged from 1.4-2.9 for PIH. Overall, ethnic variations were seen.

In Latin America, a large population based study $(n=878,680)$ was conducted by using a birth event records database (BERD) resulted that association between preeclampsia and GDM (relative risk=1.93, 95 percent CI: $1.66,2.25)$ with no ethnicity and body mass index accounted in this study (Conde-Agudelo et al., 2000).

Another perspective study of women for calcium supplementation trial to prevent pre-eclampsia showed the degree of abnormal glucose tolerance which was associated with pre-eclampsia. It showed that GDM have an increased risk of preeclampsia $(\mathrm{OR}=1.67,95$ percent $\mathrm{CI}$ : 0.92, 3.05) (Joffe et al., 1998).

Another study have been found in French including 15 maternity units to found an association GDM and almost all forms of PIH (OR=2.86, 95\% CI: 1.05, 7.83) (Vambergue et al., 2002). A number of other studies have been examined to understand the association between GDM and PIH.

\section{RESULTS}

According to epidemiological tools and the available research data, we have reached to the point that PIH and GDM have no clear association except the way of insulin resistance, present in NIDDM due to $\beta$-cells dysfunction. No other evidences are present in available researches studies and clinical data to deduce the association between these two conditions in gestation. But these studies describe that there is some impact of factors; race, ethnicity as well as perinatal care on severity and complications of hypertension state of gestation. In GDM, monitoring of glycaemia as well as blood pressure during before, during and after GDM may provide some data to find the relationship between GDM and PIH.

\section{CONCLUSION}

It is concluded that the association between Pregnancy induced hypertension and gestational diabetes mellitus is due to a unifying factor, insulin resistance. Hyperglycemia generates the increase in blood pressure, due to insulin resistance which prolongs the extent of hypertension. That's why GDM may have a role in generating as well as precipitations of the complications of PIH. PIH and GDM have high prevalence, but most of the people do not know about the severity, complications and life threatening results. More researches should be there.

\section{REFERENCES}

Alberti, K.G., Zimmet, P.Z. (1998) Definition, diagnosis and classification of diabetes mellitus and its complications. Part 1: diagnosis and classification of diabetes mellitus provisional report of a WHO consultation, Diabet Med., 15(7): 539-553. [DOI]

American Diabetes Association (2000) Gestational diabetes mellitus. Diabetes Care 23 (Suppl. 1):S77-S79. PMid:12017686

American Diabetes Association (2000) Gestational diabetes mellitus. Diabetes Care 23 (Suppl. 1): S77-S79,

Atlas of Genetic Diagnosis and Counseling (2006), Diabetic Embryopathy, 289-294

Bellamy L, Casas JP, Hingorani AD, Williams D. (2009) Type 2 diabetes mellitus after gestational diabetes: a systematic review and metaanalysis. Lancet; 373(9677):1773-1779. [DOI]

Chris L. Bryson George N. Ioannou, Stephen J. Rulyak, and Cathy Critchlow (2003) Association between gestational diabetes and pregnancy-induced hypertension, AJE; Vol. 158, No. 12.

Christopher A. Loffredo (2000) Epidemiology of Cardiovascular Malformations: Prevalence and Risk Factors. Am. J. Med. Genet. (Semin. Med. Genet.) 97:319-325. [DOI]

Conde-Agudelo A, Belizan JM. (2000) Risk factors for pre-eclampsia in a large Cohort of Latin American and Caribbean women. BJOG; 107:7583. [DOI]

Farrell T. et al. (2002). Congenital anomalies in the offspring of women with Type 1, Type 2 and gestational diabetes. Diabet. Med. 19, 322-326. [DOI]

Fiona Lyall and Ian A. Greer, (1996) The vascular endothelium in norma pregnancy and pre-eclampsia. Journal of reproduction and fertility, 1,107-116. [DOI]

Girouard J, Giguère Y, Moutquin JM, Forest JC. (2007) Previous Hypertensive Disease of Pregnancy Is Associated With Alterations of Markers of Insulin Resist.; 49: 1056-1062.

Gu H, Rong L, Sai JY, (1994) Insulin resistance and pregnancy induced hypertension , 29(12):711-3, 760.

Hod M, Merlob P, Friedman S, Schoenfeld A, Ovadia J. (1991) Gestational diabetes mellitus. A survey of perinatal complications in the 1980s, Diabetes. 1991 Dec; 40 Suppl 2:74-78. [DOI]

James M. Roberts, Gail Pearson, Jeff Cutler and Marshall Lindheimer (2003) Summary of the NHLBI working group on research on hypertension during pregnancy. Hypertension, 41: 437-445. [DOI]

Joffe GM, Esterlitz JR, et al. (1998) The relationship between abnormal glucose tolerance and hypertensive disorders of pregnancy in healthy nulliparous women. Calcium for Preeclampsia Prevention (CPEP) Study Group. Am J Obstet Gynecol; 179:1032-7. [DOI] 
Jun Zhang, Jonathan Zeisler, Maureen C. Hatch, and Gertrud Berkowitz. (1997) Oxford Journal; Vol. 19, No. 2

Kim E. Innes and Jeffrey H. Wimsatt (1999) Pregnancy-induced hypertension and insulin resistance, evidence for a connection, Vol. 78 No. 4, Pages 263-284

Leanne Bellamy, Juan-Pablo Casas, Aroon D Hingorani, David J Williams (2007) Pre-eclampsia and risk of cardiovascular disease and cancer in later life: systematic review and meta-analysis, BMJ, 335 [DOI]

Metzger BE, Coustan DR (1998) Summary and recommendations of the Fourth International Workshop-Conference on Gestational Diabetes Mellitus. Diabetes Care, 21 (Suppl. 1): B161-B167. PMid:9704245

National High Blood Pressure Education Program Working Group. (1990) Report on high blood pressure in pregnancy. Am J Obstet Gynecol; 163:1691-1712. [DOI]

Naveed Sattar, Ian A Greer (2002) Pregnancy complications and maternal cardiovascular risk: opportunities for intervention and screening? BMJ 325: 157-160. [DOI]

Palomo I, Alarcon M, Moore-Carrasco R, Argiles JM. (2006) Hemostasis alterations in metabolic syndrome, Int J Mol Med.; 18:969-974. [DOI]

Redman CW, Jefferies M. (1988) Revised definition of pre- eclampsia. Lancet, 809-812. [DOI]

Sibai BM, Gordon T, Thom E, et al. (1995) Risk factors for preeclampsia in healthy nulliparous women: a prospective multicenter study. The National Institute of Child Health and Human Development Network of Maternal-Fetal Medicine Units. Am J Obstet Gynecol; 172:642-8. [DOI]

Solomon CG, Seely EW. (2001) Brief review: hypertension in pregnancy: a manifestation of the insulin resistance syndrome? Hypertension; 37:232-9. [DOI]
Spellacy WN, Miller S, Winegar A, Peterson PQ. (1985) MacrosomiaMaternal Characteristics and Infant Complications, Obstet Gynecol. 66(2):158-161. PMid:4022478

Tara E. O'Brien, Joel G. Ray, and Wee-Shian Chan (2003) Maternal Body Mass Index and the Risk of Preeclampsia: A Systematic Overview. Epidemiology; 14: 368-374. [DOI]

Thomas A. Buchanan (2001) Pancreatic B-Cell Defects in Gestational Diabetes: Implications for the Pathogenesis and Prevention of Type 2 Diseases. JCE \& M, Vol. 86, No. 3.

Thomas A. Buchanan, Anny Xiang, Siri Kjos, Richard Watanabe (2007) What Is Gestational Diabetes? Diabetes Care, Vol. 30, Supp 2.

Tracy L. Setji, Ann J. Brown and Mark N. Feinglos (2005) Gestational Diabetes Mellitus, Clinical Diabetes, vol. 23 no. 1, 17-24. [DOI]

UIf Hanson, Bengt Persson (1993) Outcome of Pregnancies Complicated by Type 1 Insulin-Dependent Diabetes in Sweden: Acute Pregnancy Complications, Neonatal Mortality and Morbidity. Amer J Perinatol; 10(4): 330-333. [DOI]

Vambergue A, Nuttens MC, Goeusse P, et al. (2002) Pregnancy induced hypertension in women with gestational carbohydrate intolerance: the diagest study. Eur J Obstet Gynecol Reprod Biol; 102:31-5. [DOI]

WHO Consultation (1999) Definition, Diagnosis and Classification of Diabetes Mellitus and Its Complications: Report of a WHO Consultation. Part 1: Diagnosis and Classification of Diabetes Mellitus. Geneva, WHO/NCD/ NCS/99.2, World Health Org. 